\title{
Virtual Consumption: Using Player Types to Explore Virtual Consumer Behavior
}

\author{
Penny Drennan ${ }^{1}$ and Dominique A. Keeffe ${ }^{2}$ \\ ${ }^{1}$ Faculty of Information Technology, Queensland University of Technology \\ ${ }^{2}$ Faculty of Business, Queensland University of Technology \\ \{p drennan, d.keeffe\} @qut.edu.au
}

\begin{abstract}
As virtual economies begin to interact more with real world economies, it is important to consider the in-game activities that players engage in, which create and transfer game currency. Specifically, we examine products and services that players offer to each other within MMORPGs. We use Bartle's taxonomy of player types to illustrate the different behavioral approaches players have in consuming these products and services. We introduce the term virtual consumption to describe these in-game exchanges and highlight the need for further research into this phenomenon.
\end{abstract}

Keywords: player types, virtual consumption, consumer behavior.

\section{Introduction}

There is a growing body of research that explores the intersection between real and virtual world economies [2,6]. However, there have been few attempts to explore virtual consumption, which is the way that players behave while consuming in-game products and services. As real world and game economies converge and the scale of game economies increases, it is imperative to investigate the services that are offered in virtual worlds, and the behavior of players in virtual (i.e. in-game) consumption situations. This paper explores how Bartle's taxonomy of player types can be used to investigate virtual consumer behavior within the context of Massively Multi-player Online Role-Playing Games (MMORPGs). We begin by providing details about Bartle's taxonomy, followed by a brief introduction to the domain of consumer behavior. Next, we illustrate the concept of virtual consumption in an MMORPG. Finally, we propose ways that players might engage in virtual consumption situations, based on their predominant approach to MMORPGs, as described by Bartle. Finally, we outline further work aimed at exploring virtual consumption in more depth.

\section{Player Types}

While there are many studies exploring player behavior and motivation in MMORPGs [4, 9], Bartle provides the most well known and comprehensive categorization of player types [1]. He outlines four categories of behavior based on two axes of playing style. These axes 
identify the focus of the player's attention (world-oriented versus player-oriented) and describe the way the player approaches the game (action versus interaction). The intersecting axes thus form four distinct player types: killers, socializers, achievers, and explorers. Bartle has since extended this taxonomy by adding a third axis, describing behavior as either implicit or explicit for each of the four player categories outlined above [1]. However, we believe that the four original player types provide scope for an initial exploration of virtual consumer behavior, without presupposing certain types of behavior.

\section{Traditional Consumer Behavior}

Given that virtual worlds are both psychologically unique and the setting for a range of different player behaviors, we propose that virtual worlds provide the ideal environment to investigate consumer (mis)behavior because they allow players (or "consumers") to behave in a way that is realistic but uninhibited by social norms. Traditionally, consumer behavior is described as the "study of the processes involved when individuals or groups select, purchase, use or dispose of products, services, ideas or experiences to satisfy needs and desires" [8]. Consumers can engage in a range of behaviors as a response to their satisfaction or dissatisfaction with what they have purchased. However, consumers do not always behave appropriately, especially when they are dissatisfied with their purchase. One of the most extreme negative behavioral responses a consumer can engage in is retaliation, which is an aggressive behavior engaged in with the intention of getting even [5]. These behaviors can be overt or covert and include verbal or physical abuse, theft, creating a cost/loss, vandalism, and trashing [5]. All retaliatory behavior is motivated by a desire to correct inequity (whether real or psychological): it's a case of 'You got me. I got you back. Now we're even' [5, 7]. While traditional research is conducted using real life consumption situations, we propose that consumers will engage in a similar range of behaviors in virtual worlds. It is vital that we investigate virtual consumption as virtual economies meet real world economies.

\section{Consumption in MMORPGs}

MMORPGs promote consumption that is specific to the story and fantasy elements of its specific environment. For instance, studies of Guild Wars [3] indicate that players sometimes act as merchants by providing a range of goods for sale to other players. The items that they offer are the same goods offered by merchant non-player characters (NPCs), so these players do not offer a unique virtual service. However, transactions between players and player merchants shave the margins, providing lower costs and allowing players to sell items for higher prices than they can get from NPCs. Usually player merchants are higher level characters, who have gathered a large collection of items from different areas throughout the game. Similarly, other high level players will offer to act as "runners" to lower level characters. This means that they offer to quickly and safely take players through difficult sections of the game in return for game currency. Successful runners are required to be familiar with the section of the game that they are providing the service for, as well as being equipped with the skills to safely navigate the area [3]. 


\section{Player Types in Virtual Consumption}

We propose that players will approach virtual consumption situations differently depending on their dominant player type. We can examine Bartle's taxonomy of player types in light of virtual consumer behavior, by considering how each player type might act in a virtual consumption situation. Both positive and negative consumer behavior can be demonstrated by all four player types. However, we believe that retaliatory consumer behavior is more likely to be shown by killers and socializers. Conversely, achievers and explorers are more likely to provide than consume.

First, we suggest that socializers will be motivated to create and maintain positive consumption relationships with other players. When socializers experience highly satisfactory consumption situations, they are most likely to engage in positive consumer behavior, such as helping service providers or advocating on behalf of the service provider. Further, socializers would be keen to develop a closer relationship with their service provider and attempt to salvage the unsatisfactory consumption situations by using their communication skills. This might result in the player negotiating with or complaining to the service provider. A dissatisfied socializer is unlikely to engage in retaliation against a service provider. However, socializers may be motivated to retaliate against service providers if they perceive that a member of their social network has been adversely affected and is in need of support or intervention.

Second, we propose that killers are motivated to extract maximum value from their consumption experiences without regard for future interactions. A merely satisfactory experience will not prompt any particular behavior from a killer; they have received what they need from the interaction and are not likely to expend further energy prolonging the experience. However, it is when consumption situations are unsatisfactory that killers might begin to display the overt behavior that characterizes this player type. When killers are dissatisfied, we propose that they will engage in negative behaviors that are disproportionate to the event that caused them. This retaliatory behavior can escalate (depending on the situation) into verbally abusive fighting. Of all player types, killers are most likely to engage in retaliation as they perceive that there is a lack of consequence engendered by the anonymity in most MMORPGs.

Finally, achievers and explorers are less likely to engage in the extreme behavior demonstrated by socializers and killers due to their focus on the world. We suggest this is because they are the players most likely to provide products and services to other players by virtue of their world focus. Achievers are likely to have the necessary skills to complete difficult areas of the game with panache, making them candidates to offer running services. Explorers are also likely to be competent runners, as they have knowledge of quicker and safer routes through difficult parts of the game. Further, explorers are likely to be player merchants because they may have discovered artifacts in areas of the MMORPG that other players have not yet accessed. These world-focused skills put achievers and explorers in a position where they are more likely to provide rather than consume. 


\section{Conclusions and Future Work}

This paper demonstrated how Bartle's taxonomy of player types could be meaningfully applied to virtual consumption. We have explored the concept of traditional consumer behavior and how it may be mirrored in virtual worlds. We also examined possible classification of consumer behavior, by exploring Bartle's taxonomy of player types as an organizing framework. Given this preliminary exploration, there are many directions in which future work can progress. We believe that observing players will allow us to access more information about player motivations and their responses to specific consumption situations. These player studies will develop a corpus of evidence illuminating virtual consumption in MMORPGs.

\section{References}

1. Bartle, R.A.: Designing Virtual Worlds, 1st edn. New Riders Publishing, Indianapolis, Indiana (2003)

2. Castronova, E.: Virtual Worlds: A First-Hand Account of Market and Society on the Cyberian Frontier. CESifo Working Paper Series No. 618 (2001)

3. Drennan, P.: An Ethnographic Study of Player Behaviour in MMORPGs. Unpublished doctoral dissertation, University of Queensland, Australia (2007)

4. Ducheneaut, N., Yee, N., Nickell, E., Moore, R.J.: 'Alone together?' exploring the social dynamics of massively multiplayer online games. In: ACM Conference on Human Factors in Computing Systems (CHI 2006), pp. 407-416. ACM, New York (2006)

5. Huefner, J.C., Hunt, H.K.: Consumer retaliation as a response to dissatisfaction. Journal of Consumer Satisfaction, Dissatisfaction and Complaining Behavior 47, 107-117 (2000)

6. Malaby, T.: Parlaying Value: Capital in and beyond Virtual Worlds. Games \& Culture 1, 141-162 (2006)

7. Skarlicki, D.P., Folger, R.: Retaliation in the workplace: The roles of distributive, procedural, and interactional justice. Journal of Applied Psychology 82, 434-443 (1997)

8. Solomon, M.R., Dann, S., Dann, S., Russell-Bennett, R.: Consumer Behaviour: Buying, Having, Being. 1st edn. Pearson Education, Frenchs Forest, NSW (2007)

9. Yee, N.: Motivations of Play in Online Games. Journal of CyberPsychology and Behavior 9, 772-775 (2007) 